\title{
CAPILLARIA HEPATICA: ALGUNS ASPECTOS IMUNOPATOLÓGICOS DA INFECÇÃO ESPÜRIA E DA INFECÇÃO VERDADEIRA
}

\author{
Ivana Nascimento ${ }^{1}$ e Moysés Sadigursky²
}

\begin{abstract}
A fim de se observar uma possivel proteção conferida pela infecçāo espúria contra uma infecção verdadeira por Capillaria hepatica. camundongos foram inoculados com ovos não embrionados (infecção espúria) e, posteriormente, com ovos embrionados (infecção verdadeira). Anticorpos especificos da classe IgG, detectados por teste imunoenzimático (ELISA), mostraram-se elevados a partir da segunda semana do experimento. $O$ teste de hipersensibilidade cutânea tardia resultou negativo. $O$ exame das lesões do figado, assim como a contagem de ovos, utilizados como parâmetros para comparação entre os grupos de animais estudados, não apresentaram variação significativa indicando que a imunidade humoral induzida pela infecção espúria não tem potencial protetor.
\end{abstract}

\section{Palavras-chaves: Capillaria hepatica: Capilariase. ELISA.}

Capillaria hepatica è um helminto que infecta várias espécies de mamiferos ${ }^{20}$, desde roedores e animais domésticos ${ }^{18}$ a primatas ${ }^{6}$, incluindo o homem. Tem sido encontrado em quase todas as regiōes do mundo sob as mais diversas condições climáticas e ambientais 781112 .

Entretanto, apesar da ampla disseminaçào entre os animais e da capacidade dos ovos eliminados nas fezes, de embrionarem no solo e permanecerem viáveis em condiçōes diversas ${ }^{13}$, a prevalência da doença em individuos da espécie humana é muito baixa, mesmo em comunidades que vivem em condições precárias de higiene.

Com base nesses dados decidimos ampliar o estudo sobre o papel da infeç̧ão espúria por via oral e verificar sua importância na resposta imune, na possivel proteção conferida por esta contra uma infecção verdadeira posterior e ainda na imunopatologia, utilizando camundongos como animais de experimentaçào.

\section{MATERIAL E MÉTODOS}

$O$ experimento foi realizado em camundongos "Swiss", não isogênicos entre $18 \mathrm{e} 20 \mathrm{~g}$, distribuídos em seis grupos tratados, no dia " $\mathrm{O}$ " do experimento, como descrito a seguir:

Grupo I - Nove animais infectados com 20 ovos embrionados (infeç̧ão verdadeira - I.V.);

Grupo II - Quinze animais inoculados com 2500 ovos não embrionados (infecção espúria - I.E.);

1. Departamento de Biomorfologia, ICS, Universidade Federal da Bahia, Salvador-Bahia-Brasil.

2. Centro de Pesquisas Gonçalo Moniz (FIOCRUZ/UFBA). Trabalho realizado com o apoio do Conselho Nacional de Desenvolvimento Científico e Tecnológico (CNPq).

Recebido para publicação em $26 / 6 / 85$
Grupo III - Onze animais inoculados com 2500 ovos nos dias $0,7,14$ e 21;

Grupos IV e V - não foram inoculados nesta fase.

Grupo VI com oito animais conservados sem infecção, como controle normal.

Os Grupos I, II, III e IV foram infectados com 20 ovos embrionados e o grupo $\mathrm{V} \operatorname{com} 2500$ ovos não embrionados no 28 o dia do experimento.

Ovos embrionados e não embrionados para manutenção do ciclo e infecçào dos animais foram obtidos segundo a mesma técnica utilizada por Juliano $^{10}$. As inoculaçōes foram feitas por via oral utilizando-se seringas com agulha hipodermica $30 \times 8$ com ponta romba revestida por solda metálica de prata. Fez-se o cálculo do número de ovos $/ \mathrm{ml}$ contando-se $1 \mathrm{ml}$ de suspensão de ovos em càmara de Sedgwick-Rafter ${ }^{1}$. A diluiçào ou concentraçào foi feita em soluçào salina tamponada (SST) pH 7,2.

O nivel de IgG especifica anti-C. hepatica foi acompanhado mediante teste imunoenzimático (ELISA). Os soros foram obtidos por coleta de sangue do plexo retro-orbitário dos animais dos Grupos I, II, III, IV, V e VI no dia O do experimento e dos grupos I, II, III e VI nos dias 7, 14, 21 e 28. No 68\% dia do experimento todos os animais foram sacrificados obtendo-se soro a partir de sangue coletado do plexo axilar.

Para o teste imunoenzimático utilizou-se antígeno solúvel retirado de ovos não embrionados e de vermes adultos os quais foram obtidos por esmagamento manual do fígado o que permitiu coletar os vermes ainda vivos. Os ovos não embrionados foram extraidos triturando-se os figados em liqüidificador com SST $0,15 \mathrm{M}, \mathrm{pH} 7,2$ contendo $100 \mathrm{U} / \mathrm{ml}$ de penicilina e $100 \mathrm{\mu g} / \mathrm{ml}$ de estrep- 
Nascimento I, Sadigursky M. Capillaria hepatica: alguns aspectos imunopatológicos da infeção espúria e da infeç̧ão verdadeira. Revista da Sociedade Brasileira de Medicina Tropical 19: 21-25, Jan-Mar, 1986

tomicina. Após decantação o sedimento foi ressuspenso em SST $0,15 \mathrm{M}, \mathrm{pH} 7,2$ e a operação repetida até o sobrenadante ficar claro. O sedimento foi tratado com tripsina a $0,25 \%$, sob agitação. Após centrifugação a 300 g durante 10 minutos, o sedimento foi ressuspenso em SST 0,15M, pH 7.2 novamente centrifugado repetindo-se a operação três vezes. Finalmente o sedimento contendo os ovos de $C$. hepatica foi homogeneizado juntamente com os vermes adultos, em homogeneizador Porter durante 30 minutos em recipiente com gelo e centrifugado durante 10 minutos a $300 \mathrm{~g}$. O sobrenadante coletado apresentou uma concentração de proteínas da ordem de $560 \mathrm{\mu g} / \mathrm{ml}$. Este antigeno foi, então, diluido em tampão carbonato $0,05 \mathrm{M}$ pH 9.5, para concentração final de $10 \mu \mathrm{g}$ de proteina por ml. Duzentos microlitros desta solução foram colocados em cada um dos poços de placas de microtitulação (Linbro Microplate, 96 Flat botton wells. lot. no 76-381-04 Virginia 22102, USA) as quais foram incubados a $37^{\circ} \mathrm{C}$ durante, no minimo, 3 horas. Após lavagem foram adicionados duzentos microlitros do soro a ser testado, diluído 1:40 (diluição padronizada previamente) em SST/Tween realizando a reação em duplicata para cada soro. $\mathrm{O}$ antissoro, anti-IgG de camundongo produzido em cabra, conjugado com peroxidase (Sigma Chemical Co. Lot. 72F 8835). foi diluido a 1:1000. A reação foi revelada com OPD (Sigma). As leituras foram realizadas em espectrofotômetro de leitura múltipla automática (Titertek Multiskan) em $492 \mathrm{~nm}$ de comprimento de onda.
Para o teste de hipersensibilidade cutânea tardia utilizou-se antigeno solúvel obtido por homogeneização de ovos não embrionados em SST pH 7,4. $\mathrm{O}$ teste foi realizado no 64 \% dia do experimento, em cinco animais de cada grupo. Inoculou-se no coxim da pata traseira esquerda de cada animal, $50 \mu \mathrm{g}$ de proteina em $35 \mu$ de SST pH 7,4 e, no coxim da pata direita traseira, $35 \mu l$ de SST pH 7,4. A medida da espessura dos coxins das patas traseiras foi feita antes da inoculação e 2, 24 e 48 horas depois.

No 68. dia do experimento todos os animais foram sacrificados, retirando-se o fígado de cinco animais do grupo I, quatro do grupo II, sete do grupo III, oito do grupo IV, oito do grupo V e quatro do grupo VI, os quais foram submetidos à digestão por $\mathrm{KOH}$ a $5 \%$ para se fazer a contagem dos ovos em placas de Sedgwick-Rafter ${ }^{1}$. Dos animais restantes foram utilizados fragmentos de figado para exame anátomopatológico.

\section{RESULTADOS}

Através dos valores obtidos pela leitura da densidade ótica foi possivel observar uma elevação dos niveis de anticorpos a partir da segunda semana da infeç̧ão nos grupos I e II, havendo uma queda por volta da quarta semana. Entretanto, na dosagem realizada no 68. dia do experimento, observou-se significativa elevação dos niveis de IgG especifica (Figura 1).

Figura 1 - Niveis de IgG anti-C. hepatica dos grupos I, II, III e VI nos diversos dias do experimento (ELISA) Ordenada: Média das percentagens da densidade ótica Abscissa: Dia do experimento

$$
\begin{aligned}
& O \text { - Grupo I } \\
& \square \text { - Grupo II } \\
& \text { - Grupo III } \\
& \Delta \text { - Grupo VI }
\end{aligned}
$$

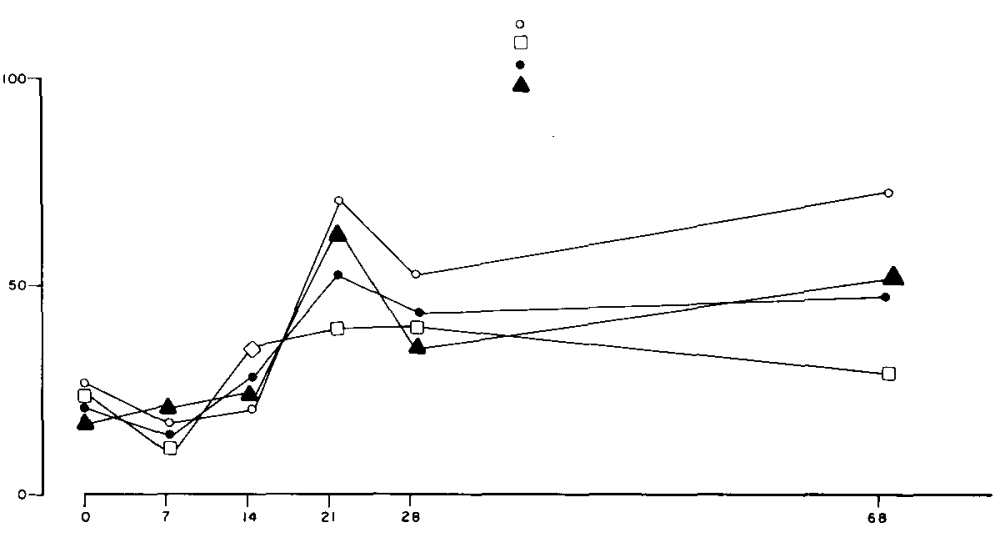


O teste de hipersensibilidade cutânea tardia não evidenciou variação significativa entre os animais dos grupos estudados.

A contagem dos ovos obtidos pela digestão em KOH $5 \%$ dos figados dos animais dos grupos I, II, III e IV não evidenciou variação significativa entre os grupos (Tabela 1).

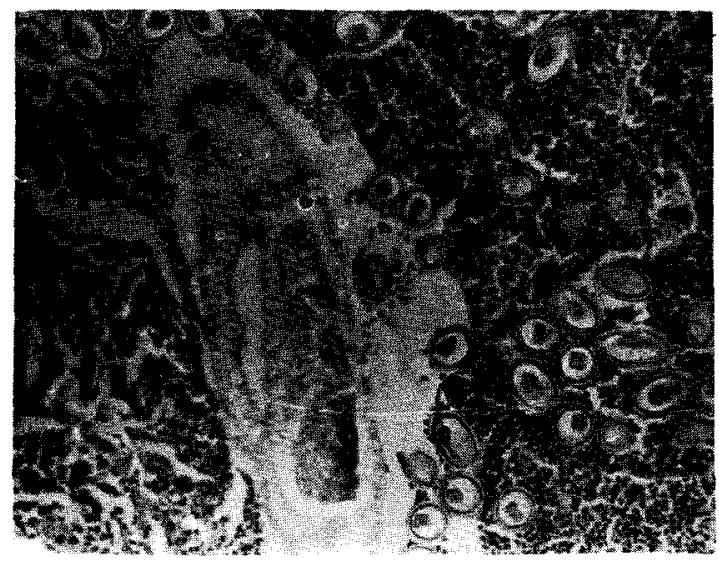

Figura 2 - Parênquima hepático com exsudato eosinofilico intenso em torno a restos de vermes adultos e ovos dispersos.

Ao exame anátomo-patologico dos animais infectados com ovos embrionados os fígados pesaram: no grupo I de 1,26 a $1,65 \mathrm{~g}(\overline{\mathrm{x}}=1,46 \mathrm{~g})$; no grupo II de 0,85 a $1,58 \mathrm{~g}(\mathrm{x}=1,19 \mathrm{~g})$; no grupo III de 1,07 a 1,67 $(\mathrm{x}=1,30 \mathrm{~g}) ;$ no grupo IV de 0,93 a $1,75 \mathrm{~g}(\mathrm{x}=1,30 \mathrm{~g})$. $A$ variação não é estatisticamente significante. A macroscopia os figados exibiam pontilhado brancoamarelado, por vezes confluente, distribuído pela superficie. Ao corte observou-se que o pontilhado

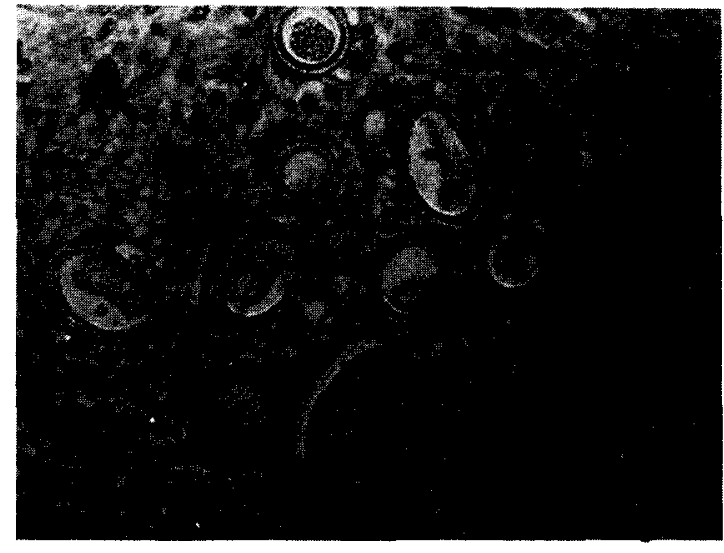

Figura 3 - Granuloma com intensa fibrose em tomo de ovos maduros.

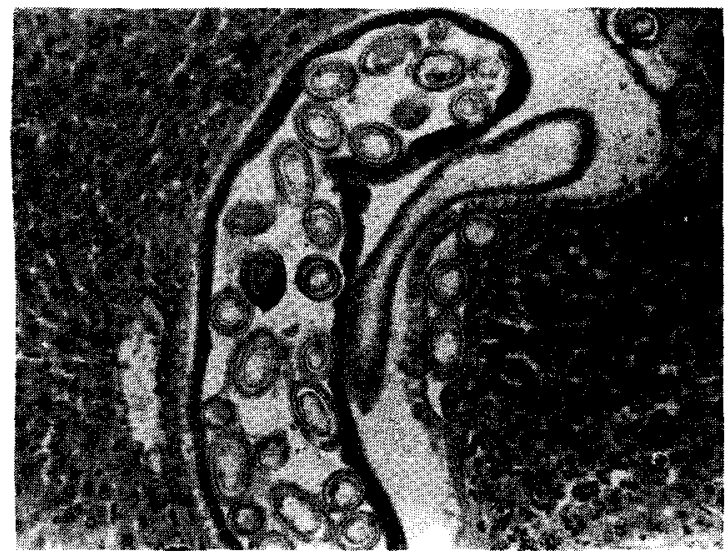

Figura 4 - Reação inflamatória discreta em torno de verme aparentemente integro.

Tabela 1 - Número de ovos de Capillaria hepatica por figado de camundongo, obtido através de digestão alcalina.

\begin{tabular}{crrr}
\hline \multicolumn{1}{c}{ I R UPOS } & \multicolumn{1}{c}{$I I I$} \\
\hline 1.056 .000 & 948.000 & 1.042 .000 & 997.000 \\
571.500 & 828.000 & 448.000 & 865.500 \\
1.212 .000 & 348.000 & 77.500 & 48.500 \\
156.500 & 341.000 & 172.000 & 56.500 \\
375.000 & 752.000 & 346.500 & 634.500 \\
893.000 & 1.021 .000 & 125.700 & 197.000 \\
679.500 & 837.000 & & 563.000 \\
& 226.000 & & \\
\hline
\end{tabular}


Nascimento I, Sadigursky M. Capillaria hepatica: alguns aspectos imunopatológicos da infecção espúria e da infeção verdadeira. Revista da Sociedade Brasileira de Medicina Tropical 19:21-25, Jan-Mar, 1986

correspondia a diminutos nódulos, de consistência firme, cujo diâmetro variava de $0,02 \mathrm{~cm}$, quando isolados, até $0,3 \mathrm{~cm}$ nas áreas de confluência. Os animais dos grupos $\mathrm{V}$ e VI não apresentaram alterações macroscópicas. $O$ exame histopatológico evidenciou lesões hepáticas em vários estágios de desenvolvimento, não só em animais de diferentes grupos como entre animais de um mesmo grupo. Alguns dos animais exibiam parênquima hepático com exsudato eosinofilico intenso em torno a restos de vermes adultos e pouca ou nenhuma fibrose. Por outro lado, alguns apresentaram o figado com granulomas bem desenvolvidos, em torno de ovos maduros, com fibrose intensa, não havendo restos de vermes. Em torno de vermes, aparentemente integros, a reação inflamatória era discreta ou inexistente com o tecido circundante bem preservado.

\section{DISCUSSÃO}

Como diversos autores demonstraram ${ }^{13} 1622, o$ camundongo é muito suscetivel à infecção por Capillaria hepatica. Mesmo com a utilização de apenas vinte ovos embrionados para a infecção todos os animais inoculados desenvolveram a doença.

A elevação dos niveis de IgG especifica a partir da segunda semana de infecção, como ficou demonstrado, através do teste imunoenzimático, corresponde ao descrito por Solomon e colaboradores 1721 que utilizaram hemaglutinação indireta e por Galvão ${ }^{9}$ Juliano $^{10}$ que fizeram imunofluorescência indireta.

A não elevação dos niveis de IgG nos animais nos quais se fez infecções semanais com ovos não embrionados (grupo III) sugere que estas infecçōes repetidas possam levar a uma supressão temporária da resposta imune humoral neste grupo.

A queda do nível de anticorpos especificos do grupo I e II a partir da 4 . semana de infecção pode ser explicado da seguinte maneira: no caso do grupo II infectado com apenas uma dose de ovos não embrionados essa época correspondendo ao fim do estímulo antigênico; no caso do grupo I parece-nos ter ocorrido um aumento do consumo de anticorpos com diminuição dos niveis de IgG sérica, pois, neste caso, que é de infeç̧ão verdadeira, a quarta semana cursa com a necrose da maioria dos vermes, liberação de grande número de ovos e exacerbação da reação inflamatória tecidual.

É fácil observar-se que quarenta dias após a reinfecção houve uma retomada dos altos niveis de anticorpos nos grupos reinoculados com ovos embrionados.

O fato de não haver variação significativa entre o número de ovos recuperados dos figados dos animais dos grupos I, II, III e IV mostra que as infecções espúrias não foram capazes de despertar uma resposta imune a ponto de tornar os animais resistentes à infecção verdadeira. Por outro lado, o fato de animais do grupo I, que foram infectados duas vezes com ovos embrionados, não apresentarem uma maior quantidade de ovos no figado, sugere que uma infecçào verdadeira protege, pelo menos parcialmente contra uma infecção verdadeira posterior, o que está de acordo com os achados de Zahner e colaboradores ${ }^{23}$.

As variaçōes histopatológicas dos figados infectados nos diversos animais, são semelhantes às encontradas no homem ${ }^{15}$.

A grande susceptibilidade do camundongo à capilariase o torna um bom modelo experimental para o estudo do desenvolvimento da patologia em si, mas não para a compreensảo dos mecanismos de resistência à mesma, que, certamente, estão presentes na espécie humana.

Parece-nos que o homem possui uma resistência natural a esta doença que acometeria basicamente roedores, e que os casos relatados na espécie humana decorreriam de uma contaminação durante periodos de queda de imunidade. Para corroborar esta hipótese existe o fato de que quase todos os casos graves ocorreram em crianças com menos de cinco anos de idade $^{3414}$, vivendo em péssimas condições sócioeconômicas ou em pacientes com alguma condiçào patológica concomitante como foi o caso relatado por Otto e colaboradores ${ }^{15}$.

É interessante notar que, nos casos apresentados por Slais ${ }^{19}$, os granulomas foram achados de necrópsia em individuos de meia-idade ou idosos que foram ao óbito por outras causas, e nos quais a $C$. hepatica estava limitada a nódulos únicos, geralmente calcificadas, observando-se apenas restos de vermes adultos, sem que houvesse desenvolvimento da doença.

\section{SUMMARY}

In order to evaluate a potential protective role of spurious infection on the development of capillaria, mice were infected with non-embrionated eggs (spurious infection) followed by inoculation with embrionated eggs (true infection). The humoral immune response was evaluated through enzymelinked immunosorbent assay (ELISA) that revealed a raise in anti-Capillaria hepatica $\operatorname{IgG}$ antibody two weeks after the first infection. Delayed type hypersensivity test was consistently negative. Histopathologic examination and the $\mathrm{C}$. hepatica egg burden from different groups didn't show any significant variation. The humoral immune response induced by spurious infection do not protect mice against a true infection.

Key words: Capillaria hepatica. Capillariasis. ELISA in capillariasis. 
Nascimento I, Sadigursky $M$. Capillaria hepatica alguns aspectos imunopatológicos da infecção espúria e da infecçào verdadeira. Revista da Sociedade Brasileira de Medicina Tropical 19: 21-25, Jan-Mar, 1986

\section{REFERÊNCIAS BIBLIOGRÁFICAS}

1. Cheever AW. A quantitative post-mortem study of schistosomiasis mansoni in man. American Journal of Tropical Medicine and Hygiene 17:38-64, 1968.

2. Chitwood BG. Capillaria hepatica from liver of Castor canadensis canadensis. Proceedings of the Helminthological Society of Washington 1:10, 1934.

3. Cochrane JC, Sagorin Z, Wilcocks MG. Capillaria hepatica infection in man. South African Medical Journal 31:751-755, 1957.

4. Ewing GM, Tilden IL. Capillaria hepatica: Report of fourth case of true human infestation. Journal of Pediatrics 48:341-348, 1956.

5. Farhang-Azad A. Ecology of Capillaria hepatica (Bancroft, 1893) (Nematoda). 1. Dynamics of infection among norway rat population of the Baltimore zoo, Baltimore, Maryland. Journal of Parasitology, 63:117122, 1977.

6. Foster AO, Johnson, CM. An explanation for the occurrence of Capillaria hepatica in human faeces suggested by the finding of three new hosts used as food. Transactions of the Royal Society of Tropical Medicine and Hygiene 32: 639-644, 1939.

7. Freeman RS, Wright KA. Factors concerned with the epizootiology of Capillaria hepatica (Bancroft, 1893) (Nematoda) in a population of Peromyscus maniculabes in Algonquim Park, Canada. Journal of Parasitology 46: 373-382, 1960.

8. Galvão VA. Capillaria hepatica, estudo da incidência em ratos de Salvador, Bahia e dados imunopatológicos preliminares. Revista da Sociedade Brasileira de Medicina Tropical 10:333-338, 1976.

9. Galvão VA. Tentativa para detectar infecção por Capillaria hepatica no homem. Revista do Instituto de Medicina Tropical de São Paulo 21:231-236. 1979.

10. Juliano RV. Patologia geral dos granulomas. Um modelo de granuloma pulmonar produzido por ovos de Capillaria hepatica em camundongos. Tese de Mestrado. Universidade Federal da Bahia, Salvador, 1980.

11. Lim BL, Yap LF, Krismansamy M. Capillaria hepatica infection of wild rodents in peninsular Malaysia. Asian Journal of Tropical Medicine and Public Health 8:354 $358,1977$.
12. Lubinsky G, Jacobsen BR, Baron RN. Wildlife foci of Capillaria hepatica infections in Manitoba. Canadian Journal of Zoology 49: 1201-1202, 1971.

13. Luttermoser GW. An experimental study of Capillaria hepatica in the rat and the mouse. American Journal of Hygiene 27: 321-340, 1938.

14. MacQwown AL. Capillaria hepatica: report of genuine and spurious cases. American Journal of Tropical Medicine 30: 761-767, 1950.

15. Otto GF, Berthrong M, Appleby RE, Rawlins JC, Wilbur O. Eosinophilia and hepatomegaly due to Capillaria hepatica infection. Bulletin of the Johns Hopkins Hospital 94:319-336, 1954.

16. Raybourne RB, Solomon GB, Loulsby EJL. Capillaria hepatica granuloma formation to eggs. II. Peripheral immunological responses. Experimental Parasitology $36: 244-253,1974$

17. Raybourne RB, Solomon GB. Capillaria hepatica, granuloma formation to eggs. III. Anti-immunoglobulin augmentation and reagin activity in mice. Experimental Parasitology 38:87-95, 1975.

18. Santos MN, Barros CSL. Capillaria hepatica: parasitismo do cão e do gato no Estado do Rio Grande do Sul. Revista de Medicina Veterinária 9: 133-140, 1973.

19. Slais J. The finding and identification of solitary Capillaria hepatica (Bancroft, 1893) in man from Europe. Folia Parasitologica (Praha) 20: 149-161, 1973.

20. Solomon GB, Handley Jr. CO. Capillaria hepatica (Bancroft, 1893) in Appalachian mammals. Journal of Parasitology 57: 142-144, 1971.

21. Solomon GB, Raybourne RB, Soulsby EJL. Serological studies on rodents infected with Capillaria hepatica. Journal of Parasitology 60:732-734, 1974.

22. Solomon GB, Soulsby EJL. Granuloma formation to Capillaria hepatica eggs. I. Descriptive definition. Experimental Parasitology 33:458-467, 1973.

23. Zahner H, Geyer E., Schmidt H, Lammler G. Immunonisierung gagen Capillaria hepatica. Die Wirkung von Erstinfektionen, roentgenattenuirten stadien, nicht embryonierten Eiern und loslichen Eiextrakten Zeitschrift für Parasitenkunde 64:17-28, 1980. 